\title{
Respiratory Uptake and Depuration Kinetics of Perfluorooctanesulfonate (PFOS) in a Marine Sandworm Species
}

\author{
Takeo Sakurai $^{1}$ (1) $\cdot$ Jun Kobayashi $^{1,2} \cdot$ Nozomi Ito $^{1} \cdot$ Shigeko Serizawa $^{1}$ • \\ Hiroaki Shiraishi $^{1} \cdot$ Tohru Yabe $^{1} \cdot$ Yuichi Ishii $^{1,3} \cdot$ Noriyuki Suzuki $^{1}$
}

Received: 23 February 2017 / Accepted: 14 June 2017 / Published online: 20 June 2017

(C) The Author(s) 2017. This article is an open access publication

\begin{abstract}
We determined the respiratory uptake and depuration kinetics of perfluorooctanesulfonate (PFOS) in Perinereis wilsoni, a polychaete sandworm used as a model species to investigate the fate of chemical pollutants in coastal environments. The sandworms were kept in gravelpacked containers, and the water levels were varied cyclically to mimic the tides. We used seawater kept at $17.1^{\circ} \mathrm{C}$. A 7-day exposure period was followed by a 9-day depuration period. The dissolved PFOS concentration averaged $28 \mathrm{ng} / \mathrm{L}$ during the exposure period. Sandworm samples were collected regularly for analysis of PFOS concentrations, and a first-order-kinetics model was applied to the concentrations. The respiratory absorption efficiency of PFOS was estimated to be $11 \%$ that of oxygen, which is higher than the corresponding estimates reported for several fish species. The estimated depuration half-life of 15 days was comparable to previously reported estimates for fish and oligochaete species. The bioconcentration factor was 470 .
\end{abstract}

Keywords Bioconcentration - Bioaccumulation · Persistent organic pollutants (POPs) $\cdot$ Absorption efficiency $\cdot$ Perfluoroalkyl acids $\cdot$ Polychaete

Takeo Sakurai

tsakurai@nies.go.jp

1 National Institute for Environmental Studies, 16-2 Onogawa, Tsukuba, Ibaraki 305-8506, Japan

2 Prefectural University of Kumamoto, 3-1-100 Tsukide, Kumamoto, Kumamoto 862-8502, Japan

3 Tokyo Metropolitan Research Institute for Environmental Protection, 1-7-5 Shinsuna, Koutou, Tokyo 136-0075, Japan
Bioaccumulation of perfluoroalkyl acids (PFAAs), including perfluorooctanesulfonate (PFOS), in aquatic organisms is of interest because these ionizable compounds persist in aquatic environments (Giesy and Kannan 2002) and because consumption of seafood is a major source of human exposure to PFAAs (Haug et al. 2010). The transfer of chemicals to aquatic organisms in marine environments deserves further investigation (Sakurai et al. 2013) because marine fish and shellfish globally account for more than half of the production from the fishery industry and of the caloric intake from aquatic organisms. A limited number of taxa have been covered by bioaccumulation kinetics studies (Kobayashi et al. 2013), and a basis for interspecies extrapolation of bioaccumulation kinetics has not been established. Invertebrates, including polychaetes, are important prey of fish and shellfish in coastal and shallow marine environments and thus represent an important route for the transfer of chemicals to higher trophic levels (Reynoldson 1987). However, the bioaccumulation kinetics of PFAAs in invertebrates, and polychaetes in particular, has not been extensively studied. The polychaete sandworm Perinereis wilsoni, also known as P. nuntia vallata, is commonly found in gravel in intertidal reef flats or rocky shores in East Asia, and other Perinereis sandworms are distributed globally (Glasby and Hsieh 2006; Imajima 1972). $P$. wilsoni has previously been used as a model species for investigating the fate of chemicals in coastal environments (Kono et al. 2010; Nurulnadia et al. 2013). In this study we determined the respiratory uptake and depuration kinetics of PFOS by $P$. wilsoni and compared our results with those for other aquatic animals. 


\section{Materials and Methods}

Sandworms identified as P. wilsoni (Park and Kim 2007) were obtained from an aquaculture farm and were acclimated to the laboratory environment for 4 days without feeding.

Cylindrical containers (polypropylene, $182 \mathrm{~mm}$ o.d., $141 \mathrm{~mm}$ high) with 4-mm-diameter holes in the bottom were packed from bottom to top with an approximately 25-mm-high layer of gravel $(6-8 \mathrm{~mm}), 0.5-\mathrm{mm}$-mesh polyethylene netting, and an approximately $70-\mathrm{mm}$-high layer of gravel (3-6 $\mathrm{mm})$. The gravel was too large to be ingested by the sandworms. It was essentially held in the containers, but the water entered and drained smoothly through the holes. The containers were placed in 200-L polyethylene tanks $(630 \mathrm{~mm} \times 850 \mathrm{~mm} \times 382 \mathrm{~mm}$ high $)$ to control the water temperature and water level. All the materials in contact with experimental water were rinsed with water and with aqueous methanol or methanol prior to use. As experimental water, we used filtered (nominal pore size, $0.1 \mu \mathrm{m}$ ) natural seawater (Sakurai et al. 2013). The lighting cycle was approximately 10-h light and 14-h dark.

We conducted exposure and control (non-exposure) treatments. A 7-day exposure period was followed by a 9-day depuration period. On day 0, about eight sandworms were introduced to each of 26 exposure containers and eight control containers (these included two extra containers for each treatment). The water level in the tanks was varied daily to mimic the tides as follows: the level was kept at $\sim 10 \mathrm{~cm}$ above the gravel surface for $18 \mathrm{~h}$ overnight (high level), at the bottom of the container for $1 \mathrm{~h}$ in the morning (low level), and then at the gravel surface for $5 \mathrm{~h}$.

The exposure medium was the interstitial seawater in the containers. For the exposure treatment, a standard methanol solution of potassium PFOS $(100 \mathrm{mg} / \mathrm{L}$, PFOS-002S, AccuStandard, New Haven, CT, USA) was diluted in two steps to make a stock solution of spiked seawater at a nominal PFOS concentration of $32 \mathrm{ng} / \mathrm{L}$ (as anion). This stock seawater was prepared daily and supplied to the tanks during the exposure period. For the control treatment, methanol-spiked seawater $(0.35 \mathrm{ppm}$ $\mathrm{v} / \mathrm{v}$, the same concentration as that used in the exposure treatment) was similarly prepared and supplied during the same period. The exposure concentration was set to allow a sufficient difference in the PFOS concentrations in sandworms between the exposure and control treatments, as well as to be as close as possible to environmentally relevant levels (Sakurai et al. 2010). On day 7 , at the end of the exposure period, the sandworms in each exposure container were transferred to unspiked seawater in a new container in a new tank. The sandworms were not fed during the exposure period but were fed daily
(0.02 g/container) with commercial fish food (Ambrose 800, Nippon Formula Feed Mfg. Co., Ltd., Japan) during the depuration period.

Normally, the temperature and $\mathrm{pH}$ of the interstitial water were monitored daily, and salinity was measured with a refractometer and the ammonia concentration was determined by the salicylate method every other day. The dissolved oxygen (DO) level in the interstitial water was measured in multiple exposure containers with a fluorescent-type sensor on days 9 and 11 during the periods of high- and gravel-surface-water-levels for a total of $\sim 20 \mathrm{~min}$.

Three sets of eight sandworms were sampled on day 0 from the pool of acclimated sandworms. Subsequently, three containers were randomly sampled on days 1, 3, 5, 7, $9,11,13$, and 16 from the exposure treatment and on days 7 and 16 from the control treatment. All sandworms collected from each sampled container were combined and treated as a composite sample. Dead sandworms were removed from the sample. For each treatment, nine individuals were randomly selected from the samples, weighed, and then returned to the corresponding sample for subsequent analysis. The sandworm samples were then kept at $-20^{\circ} \mathrm{C}$ until analysis. On each day of sandworm sampling in each treatment and on day 1 in the control treatment, approximately 20-mL portions of interstitial water were collected from each of three or more randomly selected containers in the treatment and then combined. Water samples were stored at $6^{\circ} \mathrm{C}$ until analysis.

PFOS concentrations in the samples were determined by previously reported methods with modifications (Sakurai et al. 2013). Briefly, homogenized sandworm and ground fish-food samples were spiked with $5 \mathrm{ng}$ of ${ }^{13} \mathrm{C}_{4}$-PFOS, mixed with silica gel, and then extracted with $20 \%$ aqueous methanol with an accelerated solvent extractor. The extract was cleaned up with solid-phaseextraction cartridges and then concentrated. For water samples, a 10 - to $100-\mathrm{mL}$ aliquot of each sample was filtered through glass-fiber filters. The filtrate (dissolved phase) was spiked with $1 \mathrm{ng}$ of ${ }^{13} \mathrm{C}_{4}$-PFOS, extracted with a solid-phase-extraction cartridge, and concentrated. The particulate phase (residue on filter) was also analyzed for the day-7 and day-16 samples. Identification and quantitation were carried out by injecting an aliquot of the final concentrated extract into a liquid chromatograph connected to a triple-quadrupole type tandem mass spectrometer. The detection limits were $0.1 \mathrm{ng} / \mathrm{g}$-wet and $0.09 \mathrm{ng} / \mathrm{g}$ for $1 \mathrm{~g}$-wet of sandworm and $0.5 \mathrm{~g}$ of fish-food samples, respectively, determined based on replicate analyses. The detection limits for water samples, determined from the signal-to-noise ratio of 8 on chromatograms and from 3 times the standard deviation of the method blank values, ranged from 0.6 to $2 \mathrm{ng} / \mathrm{L}$ for the samples $(30-100 \mathrm{~mL})$ designated as below the detection 
limit. A method blank was determined for each analysis batch, and the average blank value was subtracted from the sample values.

We analyzed the uptake and depuration of PFOS by the sandworms on the basis of a first-order-kinetics equation involving the whole-body PFOS concentration (Eq. 1) (Arnot and Gobas 2004):

$\mathrm{d} C_{\mathrm{b}}(t) / \mathrm{d} t=k_{\text {resp }}^{\prime} C_{\mathrm{dis}}-\left(k_{\mathrm{e}}^{\prime}+k_{\mathrm{m}}^{\prime}+k_{\mathrm{g}}\right) C_{\mathrm{b}}(t)$

where $C_{\mathrm{b}}(t)$ is the PFOS concentration in the sandworm as a function of time $t ; C_{\mathrm{dis}}$ is the dissolved concentration of PFOS in seawater; $k_{\text {resp }}$ is the rate constant for respiratory uptake, $k_{\mathrm{e}}$ is the elimination rate constant, and $k_{\mathrm{m}}$ is the rate constant for depuration due to metabolism (prime symbols indicate apparent values); and $k_{\mathrm{g}}$ is the growth rate constant of the exponential growth model of the sandworm, for which respective values were used for the exposure and depuration periods $\left(k_{\mathrm{g}[\mathrm{E}]}\right.$ or $\left.k_{\mathrm{g}[\mathrm{D}]}\right)$. The apparent rate constants $\left(k_{\text {resp }}^{\prime}\right.$ and $\left.\left[k_{\mathrm{e}}^{\prime}+k_{\mathrm{m}}^{\prime}\right]\right)$ were estimated by fitting the data to Eq. 1 (Sakurai et al. 2013) and were then corrected for the 1-h daily low-water-level period, during which uptake, elimination, and metabolic depuration were assumed not to occur (Eq. 2):

$k=(24 / 23) k^{\prime} \quad\left(\right.$ for $k_{\text {resp }}, k_{\mathrm{e}}$ and $\left.k_{\mathrm{m}}\right)$

Depuration half-life $\left(t_{1 / 2}\right)$ was calculated as (ln 2)/ $\left(k_{\mathrm{e}}+k_{\mathrm{m}}\right)$. The absorption efficiency of PFOS at the respiratory surfaces was estimated according to Eq. 3, by assuming that the respiratory uptake of PFOS was proportional to that of oxygen $\left(\mathrm{O}_{2}\right)$ (Sakurai et al. 2013):

$\alpha^{*}=k_{\text {resp }} D O / r$

where $\alpha^{*}$ is the respiratory absorption efficiency of PFOS relative to that of $\mathrm{O}_{2}$, and $r$ is the body-mass-specific $\mathrm{O}_{2}$ consumption rate of the sandworm. The uncertainties of the estimated parameters were estimated based on the propagation of uncertainty (Joint Committee for Guides in Metrology 2008).

We determined $r$ by measuring the decrease of DO in a cylindrical airtight glass vessel packed with the gravel to a height of $95 \mathrm{~mm}$. Eight sandworms were introduced to the vessel and acclimated overnight under a gentle flow of seawater. Then the vessel was filled with fresh seawater, capped, left for $2 \mathrm{~h}$, and turned upside down gently (to avoid injuring the sandworms) to achieve homogeneous DO in the vessel. Consumed $\mathrm{O}_{2}$ mass was calculated from the difference between the DO levels at the start and end of the measurement multiplied by the volume of water in the vessel. Three measurements were made using different sets of individuals (average mass, $0.42 \pm 0.11 \mathrm{~g}$-wet), and the control value determined using a vessel containing only gravel and seawater was subtracted.

\section{Results and Discussion}

During the experiment, the interstitial water in the containers had an average \pm SD (both treatments) temperature of $17.1 \pm 0.2^{\circ} \mathrm{C}$, salinity of $36 \% \circ \pm 0 \%$, pH of $8.1 \pm 0.0$, and $\mathrm{NH}_{3}-\mathrm{N}$ concentration of $0.01 \pm 0.01 \mathrm{mg} / \mathrm{L}$. The time-weighted average DO in the interstitial water was $91 \%$ of saturation, and this value was used for the kinetics calculations.

In both treatments, the average mass of the sandworms naturally decreased during the exposure period and increased during the depuration period. The sandworms weighed $0.44 \pm 0.07 \mathrm{~g}$-wet per individual at the start of the experiment. The $k_{\mathrm{g}[\mathrm{E}]}$ values were estimated at $-0.012 \pm 0.018$ and $-0.023 \pm 0.021$, and the $k_{\mathrm{g}[\mathrm{D}]}$ values were estimated at $0.020 \pm 0.013$ and $0.027 \pm 0.015$, for the exposure and control treatments, respectively (values after \pm are standard error for $k_{\mathrm{g}}$ ). Mortality was $2.2 \%$ and $6.8 \%$ for the exposure and control treatment, respectively, during the experiment.

In the exposure treatment, $C_{\mathrm{dis}}$ averaged $28 \pm 21 \mathrm{ng} / \mathrm{L}$ during the exposure period. The PFOS concentration in the particulate phase (3.2 ng/L on day 7) made only a minor contribution to the PFOS concentration in the water, and the average $C_{\mathrm{dis}}$ was used for the kinetics analysis. The PFOS concentration was below the detection limit in the water samples from the control treatment and in the water samples from the depuration period of the exposure treatment. In the exposure treatment, $C_{\mathrm{b}}$ increased during the exposure period and decreased thereafter (Fig. 1). In the control treatment, $C_{\mathrm{b}}$ was stable throughout the experiment, and the average concentration

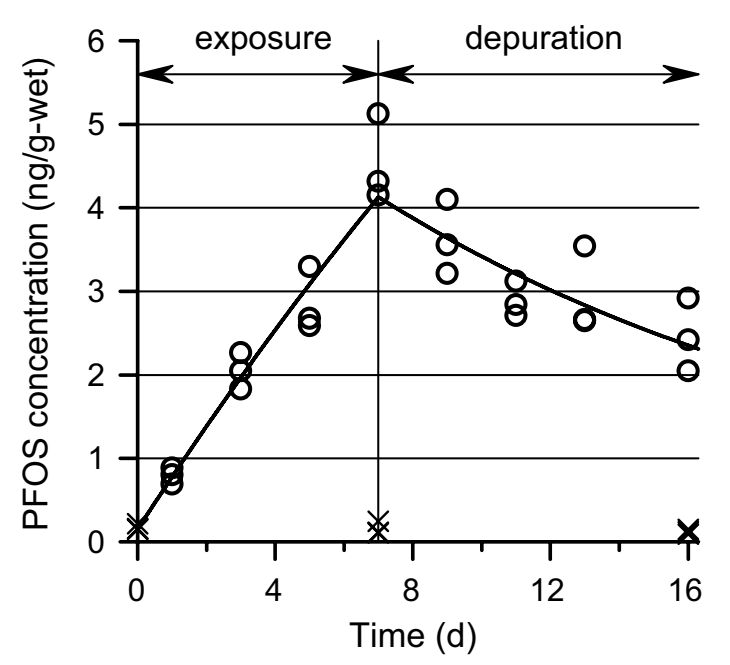

Fig. 1 PFOS concentrations in sandworm samples from the exposure treatment (circles) and the control treatment and day- 0 samples (crosses). The curve shows the first-order-kinetics model (Eq. 1) fitted to the exposure treatment data 
$(0.15 \mathrm{ng} / \mathrm{g}$-wet) calculated from all the data, including the day- 0 data, was subtracted from $C_{\mathrm{b}}$ in the exposure treatment before fitting to the model. The PFOS concentration was below the detection limit in the fish food.

We measured $r$ to be $62 \pm 9.8 \mu \mathrm{g}-\mathrm{O}_{2} /($ g-wet $\mathrm{h})$, which is comparable to previously reported $r$ values for this and related species. Empirical relationships, reported by Kristensen (1981), between $r$ and the body mass of 3 Nereis sandworm species at a salinity of $20 \%$ and at $16^{\circ} \mathrm{C}$ predict a resting $r$ of $42-70 \mu \mathrm{g}-\mathrm{O}_{2} /(\mathrm{g}$-wet $\mathrm{h}$ ) for a body mass of $0.42 \mathrm{~g}$-wet. Yoshida (1972) reported the $r$ of $P$. nuntia vallata as $33 \mu \mathrm{g}-\mathrm{O}_{2} /(\mathrm{g}$-wet $\mathrm{h}$ ) at a salinity of $32.6 \%$ and at $20^{\circ} \mathrm{C}$ for individuals weighing $0.08-0.3 \mathrm{~g}$. The lower value than the present study may be because Yoshida measured the rate in only seawater without gravel, which is not the normal habitat of this species.

We compared the values of the kinetics parameters obtained in this study (Table 1) to previously reported values for other aquatic species. The respiratory absorption efficiency of PFOS was estimated to be 0.11 that of $\mathrm{O}_{2}$. This value is low compared to values typically reported for hydrophobic neutral compounds in fish (Kobayashi et al. 2013; McKim et al. 1985), probably because of the presence of the charged sulfone group in PFOS. However, the value is higher than the values estimated for PFOS in several fish species (0.007-0.095) (Sakurai et al. 2013). The PFOS $k_{\text {resp }}$ value was in the same range as reported wholebody values for several fish species and an oyster species [5.3-53 L/(kg-wet day)] (Jeon et al. 2010; Martin et al. 2003; Sakurai et al. 2013).

The value of $k_{\mathrm{e}}+k_{\mathrm{m}}$ for PFOS corresponded to a halflife of 15 days and was similar to the value for a freshwater oligochaete $\left(0.038\right.$ day $^{-1}$; Higgins et al. 2007) and the whole-body values for the several fish species (Martin et al. 2003; Sakurai et al. 2013) but was lower than that for the oyster (0.10-0.42 day ${ }^{-1}$; Jeon et al. 2010). The bioconcentration factor $(\mathrm{BCF})$, calculated as $k_{\text {resp }}$ divided by $\left(k_{\mathrm{e}}+k_{\mathrm{m}}\right)$, was 470 , which is slightly lower than the range for the fish species (720-2800; Martin et al. 2003; Sakurai et al. 2013)

Table 1 Kinetics parameters for respiratory uptake and depuration of PFOS in the sandworm Perinereis wilsoni ${ }^{\mathrm{a}}$

\begin{tabular}{|c|c|c|c|}
\hline Parameter & Unit & Point estimate & $95 \% \mathrm{CI}$ \\
\hline$k_{\text {resp }}$ & $\begin{array}{c}\mathrm{mL} \mathrm{g}^{\mathrm{g}-\text { wet }^{-1}} \\
\text { day }^{-1}\end{array}$ & 22 & $7.9-70$ \\
\hline$\alpha^{*}$ & & $11 \%$ & $3.9 \%-30 \%$ \\
\hline$k_{\mathrm{e}}+k_{\mathrm{m}}$ & day $^{-1}$ & 0.047 & $0.027-0.068$ \\
\hline$t_{1 / 2}^{b}$ & day & 15 & $10-26$ \\
\hline
\end{tabular}

${ }^{\mathrm{a}}$ Average mass $=0.44 \mathrm{~g}$-wet at the start of the experiment

${ }^{\mathrm{b}} t_{1 / 2}=(\ln 2) /\left(k_{\mathrm{e}}+k_{\mathrm{m}}\right)$ and 1 order of magnitude higher than the value for the oyster (31-86; Jeon et al. 2010).

Acknowledgements Part of this study was conducted under a contract titled "Investigation on the transfer of persistent organic pollutants from sediment and water to aquatic organisms" with the Ministry of the Environment of Japan. This paper does not necessarily represent the views of the ministry.

Open Access This article is distributed under the terms of the Creative Commons Attribution 4.0 International License (http:// creativecommons.org/licenses/by/4.0/), which permits unrestricted use, distribution, and reproduction in any medium, provided you give appropriate credit to the original author(s) and the source, provide a link to the Creative Commons license, and indicate if changes were made.

\section{References}

Arnot JA, Gobas FAPC (2004) A food web bioaccumulation model for organic chemicals in aquatic ecosystems. Environ Toxicol Chem 23:2343-2355. doi:10.1897/03-438

Giesy JP, Kannan K (2002) Perfluorochemical surfactants in the environment. Environ Sci Technol 36:146A-152 A doi:10.1021/ es022253t

Glasby CJ, Hsieh HL (2006) New species and new records of the Perinereis nuntia species group (Nereididae: Polychaeta) from Taiwan and other Indo-West Pacific shores. Zool Stud 45:553-577

Haug LS et al (2010) Diet and particularly seafood are major sources of perfluorinated compounds in humans. Environ Int 36:772778. doi:10.1016/j.envint.2010.05.016

Higgins CP, McLeod PB, MacManus-Spencer LA, Luthy RG (2007) Bioaccumulation of perfluorochemicals in sediments by the aquatic oligochaete Lumbriculus variegatus. Environ Sci Technol 41:4600-4606. doi:10.1021/es062792o

Imajima M (1972) Review of the annelid worms of the family Nereidae of Japan, with description of five new species or subspecies. Bull Natl Sci Mus Tokyo 15:37-153

Jeon J, Kannan K, Lim HK, Moon HB, Ra JS, Kim SD (2010) Bioaccumulation of perfluorochemicals in Pacific oyster under different salinity gradients. Environ Sci Technol 44:2695-2701. doi:10.1021/es100151r

Joint Committee for Guides in Metrology (2008) Guides to the expression of uncertainty in measurement. JCGM 100:2008.

Kobayashi J et al (2013) Respiratory uptake kinetics of neutral hydrophobic organic chemicals in a marine benthic fish, Pseudopleuronectes yokohamae. Chemosphere 93:1479-1486. doi:10.1016/j.chemosphere.2013.07.031

Kono K, Tanaka H, Koyama J (2010) Dioxin transfer from sediment to the infaunal surface deposit-feeding polychaete Perinereis nuntia in a laboratory-rearing experiment. Environ Toxicol Chem 29:1512-1519. doi:10.1002/etc.177

Kristensen E (1981) Direct measurement of ventilation and oxygen uptake in three species of tubicolous polychaetes (Nereis spp.). J Comp Physiol B 145:45-50. doi:10.1007/bf00782592

Martin JW, Mabury SA, Solomon KR, Muir DCG (2003) Bioconcentration and tissue distribution of perfluorinated acids in rainbow trout (Oncorhynchus mykiss). Environ Toxicol Chem 22:196204. doi:10.1002/etc.5620220126

McKim J, Schmieder P, Veith G (1985) Absorption dynamics of organic chemical transport across trout gills as related to octanolwater partition coefficient. Toxicol Appl Pharmacol 77:1-10. doi:10.1016/0041-008X(85)90262-5 
Nurulnadia M, Koyama J, Uno S, Kokushi E, Bacolod E, Ito K, Chuman Y (2013) Bioaccumulation of dietary endocrine disrupting chemicals (EDCs) by the polychaete, Perinereis nuntia. Bull Environ Contam Toxicol 91:372-376. doi:10.1007/ s00128-013-1073-9

Park T-S, Kim W (2007) A taxonomic study on Perinereis nuntia species group (Polychaeta: Nereididae) of Korea. Korean J Syst Zool 23:75-85. doi:10.5635/KJSZ.2007.23.1.075

Reynoldson TB (1987) Interactions between sediment contaminants and benthic organisms. Hydrobiologia 149:53-66. doi:10.1007/978-94-009-4053-6_6
Sakurai $\mathrm{T}$ et al (2010) Spatial, phase, and temporal distributions of perfluorooctane sulfonate (PFOS) and perfluorooctanoate (PFOA) in Tokyo Bay, Japan. Environ Sci Technol 44:4110 4115. doi:10.1021/es1007609

Sakurai T et al (2013) Transfer kinetics of perfluorooctane sulfonate from water and sediment to a marine benthic fish, the marbled flounder (Pseudopleuronectes yokohamae). Environ Toxicol Chem 32:2009-2017. doi:10.1002/etc.2270

Yoshida S (1972) Study on the aquaculture of the Perinereis nuntia sandworm IV. Basic knowledge related to rearing. Aquiculture 20:27-35 (Japanese) 